
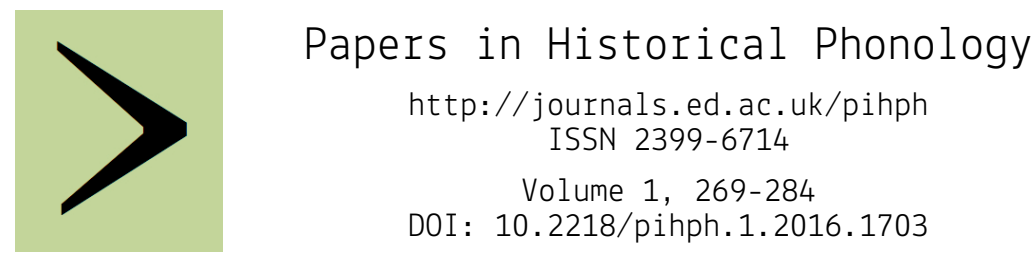

DOI : $10.2218 /$ pihph.1.2016.1703

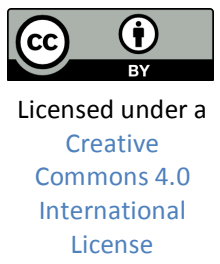

\title{
The origins of Japanese $h$ from an element-based perspective
}

\author{
PHILLIP BACKLEY \\ KUNIYA NASUKAWA \\ Tohoku Gakuin University, Japan
}

\begin{abstract}
This paper examines the historical and phonological properties of Japanese $h$ in an Element Theory approach (Nasukawa 2005, Backley 2012). It argues that the element $|U|$ is naturally weak in Japanese, which accounts for two synchronic idiosyncrasies - the restricted distribution of labials and rounded vowels, and the patterning of $h$ with labials. The analysis also offers insights into how diachronic change may be implemented. In modern Japanese, labiality is phonetically weak: the 'rounded' segments $u / w$ are produced as unrounded $[\mathrm{w}] /[\mathrm{u}]$, while labial $p$ is banned from certain contexts. These facts suggest that $|\mathrm{U}|$ is also phonologically weak in Japanese, which is expressed in terms of structural headedness: headed (strong) $|\mathrm{U}|$ represents labials while non-headed (weak) $|\mathrm{U}|$ represents velars (Backley \& Nasukawa 2009). Moreover, Japanese $|\mathrm{U}|$ has become weak, giving it unrestricted distribution in (nonheaded) velars but a contextually conditioned distribution in (headed) labials. The restriction on labials is captured by claiming that for headed $|\underline{U}|$ to be realised, it must co-occur with another 'dark' element. The division between dark $\{|\mathrm{A}|,|\mathrm{U}|,|\mathrm{L}|\}$ and light elements $\{|\mathrm{I}|,|\mathrm{H}|,|\mathrm{P}|\}$ is grounded in acoustics but also has an impact on phonological patterns cross-linguistically, such as the behaviour of $h$ and labials in Japanese.
\end{abstract}

\section{Introduction}

In this paper we discuss a case of synchronic segmental variation which is informative in two respects. Firstly, it provides insights into the nature of the Element Theory model of segmental structure (Backley 2011, 2012; Cyran 2010; Harris \& Lindsey 1995; Nasukawa 2005). In particular, it demonstrates how phonetic interpretation can be influenced by the relations that hold between elements in the same 
expression. Secondly, it sheds light on certain characteristics of the historical phonology of Japanese, the language in which the variation is observed. Using an element-based approach to melodic representation, we begin by describing aspects of the sound system of Japanese before focusing on one particular set of patterns involving the element $|\mathrm{U}|$. It will be argued that these patterns reveal how the $|U|$ element in Japanese has become inherently weak over time when compared with $|\mathrm{U}|$ in other languages. This has impacted directly on the bilabial stop $p$, which in earlier forms of the language had a free distribution. In the present-day language this consonant is restricted to the head portion of a geminate or partial geminate (except in loanwords), having been supressed in all other contexts. This diachronic weakening effect has meant that consonants that have descended historically from labials now fail to display some of the typical characteristics (e.g. place properties) of labials. In the same way, some 'rounded' vowels are now produced without any discernible lip rounding.

On the basis of these observations, we claim that the weakening of $|\mathrm{U}|$ has led to the emergence of a particular structural condition in the segmental phonology of modern Japanese-namely, that in order for labiality/rounding to be phonetically interpreted, the $|\mathrm{U}|$ element which is responsible for contributing labiality/rounding to an expression must be supported by another element from the same group of 'dark' elements. And if this structural support is not available, then the labial properties usually associated with the $|\mathrm{U}|$ element are suppressed. The result of this suppression is that labial consonants undergo lenition of one kind or another while 'back rounded' vowels are realised merely as 'back' (and unrounded). Our argument helps to strengthen the claim made elsewhere (Backley \& Nasukawa 2009, Backley 2011) that the set of elements naturally divides into two subsets, the 'dark' elements and the 'light' elements. This division will be motivated in section 4 , which is preceded by a general discussion of the element-based approach itself.

\section{Elements}

Element Theory exists in various forms (Backley 2012). Here we assume a 'standard' version of the model which employs a total of six elements: three resonance elements $|\mathrm{A}||\mathrm{I}||\mathrm{U}|$ and three non-resonance elements $|\mathrm{P}||\mathrm{H}||\mathrm{L}|$. The resonance elements represent the place properties of vowels and consonants, while the remaining nonresonance elements express the source, laryngeal and tonal properties which mainly characterise consonants.

First and foremost, elements are abstract units of structure which represent the broad phonological categories that are specified in lexical 
representations. The way in which these categories are phonetically realised can vary between one language and another, and even between one speaker and another. In fact, phonetic variation is an inherent characteristic of the Element Theory approach. For example, a syllable nucleus containing just the element $|\mathrm{A}|$ could be interpreted as [a] in some languages, as a more back vowel [a] in other languages, or as a centralised $[\Lambda]$ in other languages such as English. But if these phonetic variants $[a],[a]$ and $[\Lambda]$ display similar contrastive and/or phonological behaviour (i.e. that of an unmarked low vowel) then we expect them to have the same phonological structure $|\mathrm{A}|$.

Elements are subject to phonetic variation because, unlike standard features such as [+back], [-high] and [+continuant], which refer to speech production (articulation), elements are associated with acoustic properties. Each element is linked to a particular pattern in the speech signal, and crucially, each acoustic pattern can be reproduced (articulated) by speakers in different ways. The principal acoustic patterns for the six elements are as follows.

(1a) Resonance elements

|I low F1 with high spectral peak (F2-F3 convergence)

$|\mathrm{U}|$ low spectral peak (lowering of all formants)

$|\mathrm{A}|$ energy mass, central frequency range (F1-F2 convergence)

(1b) Source/laryngeal elements

|?| abrupt and sustained drop in energy

$|\mathrm{H}|$ aperiodicity, noise

|L| periodicity, murmur

The resonance elements in (1a) refer to formant structure - not to the specific frequency values of formants, but to general frequency patterns that capture the way energy is distributed across the spectrum. Meanwhile, the non-resonance elements in (1b) refer to other acoustic patterns that are relevant to spoken language, such as the highfrequency noise energy in $|\mathrm{H}|$ and the low-frequency murmur in $|\mathrm{L}|$. $^{1}$ The linguistic role of these acoustic patterns is to identify the phonological categories in (2). Note that an element may appear in either a nuclear (vowel) structure or a non-nuclear (consonant) structure, although we do find variation in the way elements are distributed cross-linguistically.

\footnotetext{
${ }^{1}$ For a description of the acoustic properties of elements, see Harris \& Lindsey (1995), Nasukawa \& Backley $(2008,2011)$, Backley \& Nasukawa $(2009,2010)$ and references therein.
} 
(2a) Resonance elements

\author{
nuclear \\ |I| front vowels \\ $|\mathrm{U}|$ rounded vowels \\ |A| non-high vowels
}

(2b) Source/laryngeal elements

$\begin{array}{ll} & \text { non-nuclear } \\ |\mathrm{P}| & \text { oral/glottal occlusion } \\ |\mathrm{H}| & \text { aspiration, voiceless } \\ |\mathrm{L}| & \text { nasality, obstruent voicing }\end{array}$

\author{
non-nuclear \\ coronal: dental, palatal place \\ dorsal: labial, velar place \\ guttural: uvular, pharyngeal place
}

Unlike features, elements can be pronounced individually. For example, the simplex expression $|\mathrm{I}|$ is a well-formed structure with the phonetic interpretation [i] (in a nucleus) or [j] (in an onset). From the fact that this expression contains only one element it follows that it has just one marked linguistic property (here, palatal resonance). Usually, however, elements combine to form compounds with multiple marked properties. Element combinations are asymmetrical; that is, when two elements combine they form a head-dependent relation in which the head element is phonologically stronger or physically more prominent than the dependent (or non-head). As a result of this asymmetry, any given element will have at least two phonetic realisations, depending on whether it functions as a head or a non-head. For example, $|\mathrm{H}|$ represents the audible release phase in voiceless stops, but as a head element $|\underline{\mathrm{H}}|^{2}$ it is realised as a more salient form of stop release namely, aspiration. Note that voiceless stop release and aspiration are both manifestations of the same acoustic property, aperiodic noise. They differ only in strength or prominence.

The $|U|$ element provides another example of how phonetic interpretation is affected by an element's headed status: in consonants, non-headed $|\mathrm{U}|$ is interpreted as velar resonance and headed $|\underline{\mathrm{U}}|$ as labial resonance (Backley \& Nasukawa 2009: 6ff). At first sight, it may seem unlikely that a single element should have two such different realisations; after all, velars and labials have quite distinct articulatory properties. From an acoustic point of view, however, velar resonance (figure 1) and labial resonance (figure 2) are remarkably similar, with both displaying a falling spectral pattern in which acoustic energy is

\footnotetext{
2 By convention, head elements are underlined.
} 
concentrated at the lower end of the frequency range. The difference between them mainly concerns the sharpness of this fall.

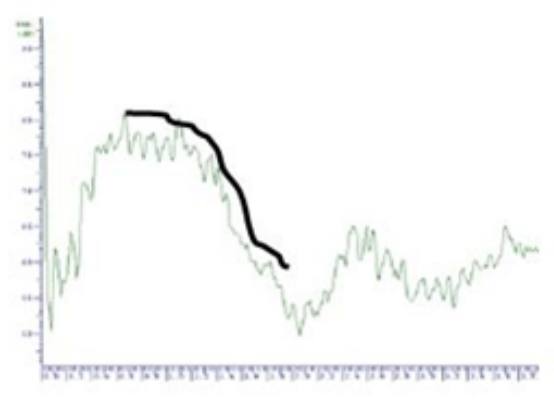

Figure 1: spectral pattern in velars

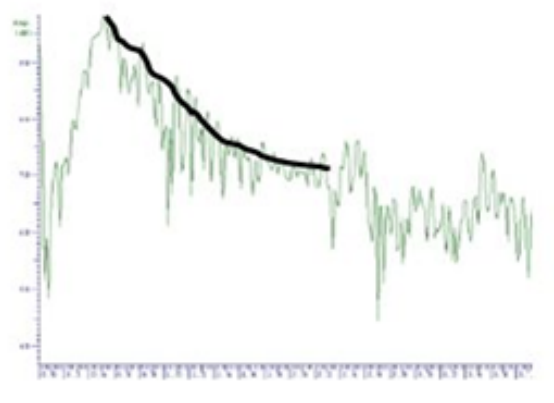

Figure 2: spectral pattern in labials

Clearly, this acoustic similarity is not enough on its own to make the case for representing velars and labials with the same element. But there is also phonological evidence to support a structural link between velars and labials. (In fact, given that elements are units of phonological structure, we expect them to have primarily a phonological motivation.) The evidence for uniting velars and labials comes from natural classes: in many languages including English, diachronic changes are reported in which velars and labials behave as a single group to the exclusion of all other place categories (Backley 2011). In Old English, for example, voiced stops became fricatives foot-internally; this process affected velars (3a) and labials (3b) but not coronals (3c).

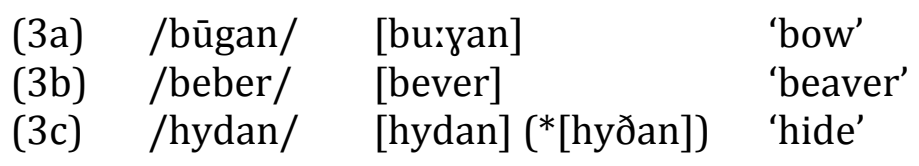

When two phonological categories regularly interact, it suggests that they are structurally close. And in Element Theory terms, a close structural relation is expressed through element sharing. Following Backley \& Nasukawa (2009) and Backley (2011), we assume that velars and labials are represented by the same element |U|. The two categories are nevertheless contrastive, so they must have (at least minimally) distinct structures. This distinction is captured by a difference in headedness, the phonological evidence indicating that labials have headed $|\underline{\mathrm{U}}|$ while velars have non-headed $|\mathrm{U}|$.

In the following section we discuss the behaviour of headed $|\underline{U}|$ and non-headed $|\mathrm{U}|$ in Japanese, showing how the difference between the two is related to phonological weakness. 


\section{Segmental patterns in Japanese}

\subsection{Labiality in Japanese consonants}

Like almost all languages, Japanese distinguishes between labials with headed $|\underline{U}|$ and velars with non-headed $|\mathrm{U}|$. What is unusual about Japanese, however, is that the $|\mathrm{U}|$ element itself appears to be relatively weak in both consonants and vowels. Let us first consider the consonant system. For some time during the history of Japanese the strong version of $|\mathrm{U}|$ - i.e. headed $|\underline{\mathrm{U}}|$, which is present in labials - has been a target for lenition. And consequently, in the modern language the labial stop $p$ has a restricted distribution (cf. velars, which are abundant and have a free distribution). For example, $p$ cannot occur word-initially except in loanwords (e.g. party, papa) and mimetic words (e.g. pika-pika 'shiny'). ${ }^{3}$

There is little doubt that initial $p$ did exist in Old Japanese (Ueda 1898), but over time it has been subject to various forms of weakening. For example, by the eighth century word-initial $p$ had spirantised to a fricative $[\phi]$ (Shibatani 1990). Then by the Muromachi period (13361573) a further lenition effect had taken place and $[\phi]$ had lost its labial properties altogether (Komatsu 1981, Martin 1987). The outcome was debuccalisation to a placeless [h]. The relevant lenition path is illustrated by the examples below (reconstructed forms are marked with *).

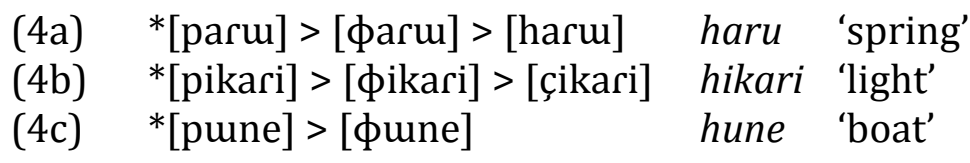

Note that it is possible for $h$ to receive additional colouring from the following vowel, hence the palatalised [c]] in /hikari/ [çikari] (4b) and the labialised $[\phi]$ in /hune/ [Qune] (4c). The relevant point, however, is that the original word-initial $p$ has lost its independent labial property. It is worth noting that this loss of labiality in the obstruent system has a parallel in the sonorant system, where the labial glide $w$ (often transcribed as [u]]) was lost in the sequences $w i, w u$ and $w o$ when they merged with the vowels $i, u$ and $o$ respectively. The

\footnotetext{
${ }^{3}$ Following Itô \& Mester (1999) and Vance (1987), we assume that the Japanese lexicon is made up of distinct strata (i.e. native Japanese words, Sino-Japanese words, recent (mainly Western) loanwords, and mimetic words) and that each stratum may display its own phonological characteristics.
} 
suppression of labial $w$ before $i / u / o$ appears to have begun much earlier than $h$-lenition (Tsukishima 1964: 29, Okumura 1972: 99-102).

Although word-initial $p$ has long been absent from the standard language, as described above, it has nevertheless been preserved in some modern dialects of Japanese. This has led to a number of word pairs such as those in (5), in which the standard (Tokyo dialect) form begins with $h$ because it is the outcome of lenition, whereas the nonstandard dialect form is $p$-initial or $\phi$-initial (data from Martin 1987).

$$
\begin{array}{lll}
\multicolumn{2}{l}{\text { standard (Tokyo) }} & \multicolumn{2}{l}{\text { non-standard }} \\
\text { hana 'flower' } & \text { pana } & \text { (Miyako dialect) } \\
\text { ha 'leaf' } & \text { фaa } & \text { (Shuri dialect) } \\
\text { hanasu 'speak' } & \text { panasu } & \text { (Tashiro-buraku dialect) }
\end{array}
$$

The labial stop $p$ was also subject to weakening between vowels. Again it first spirantised to a fricative [ $\phi]$, then later it became a glide $w$ before eliding altogether (although $w$ was preserved before the vowel $a$, as in (6c)).

$$
\begin{aligned}
& \text { *[6ipo }]>\text { [6iфo }]>\text { [6iwo }]>\text { [6io] shio 'salt' } \\
& * \text { [ipe] }>[\mathrm{i} \phi \mathrm{e}]>[\mathrm{ije}]>[\mathrm{ie}] \quad \text { ie 'house' } \\
& \text { (6c) *[kapa] }>[\mathrm{ka \phi a}]>[\text { kawa }] \quad \text { kawa 'river' }
\end{aligned}
$$

And once again, some dialects of Japanese have implemented these changes more readily than others. For example, most varieties of modern Japanese, including the standard Tokyo dialect, have the verb stem yawarag- 'get soft' with word-internal $w$. This corresponds to yaфarak- in the more conservative Shuri dialect (Okinawa), where the lenition of $p$ has developed only to the fricative stage, and to the related adjective yapaara-sen 'is soft' in the Nakajin dialect (also Okinawa), where there appears to have been no lenition at all. On the other hand, there are also some Ryukyuan (Okinawan) dialects in which lenition has progressed to the point where the labial consonant has elided altogether, giving the form yaarak- (Martin 1987: 12).

As a result of the lenition effects shown in (4) and (6), historical *p is no longer interpreted in modern Japanese either word-initially or in intervocalic position. Below we argue that these effects may be attributed to the inherent weakness of the $|\mathrm{U}|$ element in Japanese. We also consider the contexts where ${ }^{*} p$ has survived in the modern language. Before that, we turn to the fate of labiality in vowels. 


\subsection{Rounding in Japanese vowels}

The apparent weakness of $|\mathrm{U}|$ in Japanese also influences the vowel system. As shown in (1a), the main acoustic characteristic of $|U|$ is formant lowering which, in the case of vowels, speakers can achieve by adopting a high back tongue position. We therefore assume that the vowels $[\mathrm{u}]$ and $[\mathrm{u}]$ are both represented by the $|\mathrm{U}|$ element, because both are produced with precisely this gesture. Recall, however, that an element may be present either in its headed (stronger) or in its nonheaded (weaker) form. If $|\underline{\underline{U}}|$ is headed, it is interpreted as a stronger or exaggerated version of the basic acoustic pattern - that is, with an even greater concentration of spectral energy at lower frequencies. To achieve this extra effect, speakers are required to introduce lip rounding in addition to a high back tongue position, since rounding also contributes to formant lowering. On this basis we claim that unrounded $[\mathrm{u}]$ is represented by non-headed $|\mathrm{U}|$ and rounded $[\mathrm{u}]$ by headed $|\underline{\mathrm{U}}|$. This difference is pertinent to the present discussion because most native speakers of Japanese realise the high back vowel $u$ as an unrounded $[\mathrm{w}]$, which indicates that its structure has the weaker, nonheaded $|\mathrm{U}|$.

Support for Japanese $u$ (i.e. [u]) as non-headed $|\mathrm{U}|$ comes from the phonological behaviour of this vowel, which displays the characteristics of a default vowel. For example, it regularly appears in loanwords to fill (what would otherwise be) an empty nucleus - a role usually associated with weak, non-peripheral vowels such as unrounded [u] rather than with strong peripheral vowels such as rounded [u]. Moreover, in the same way that non-headed $|U|$ underlies the unrounded vowel [u], it also underlies the consonantal equivalent of [u], the Japanese non-rounded glide [u], e.g. wakai [ulakai] 'young'. This departs from most other languages, where the rounded vowel [u] is paired with the rounded glide [w].

To summarise, labiality in consonants and rounding in vowels are disfavoured in Japanese: labial consonants have a limited distribution, as they have mostly been suppressed as a result of lenition; and the vowel/glide pair $u / w$, which we expect to be rounded, is actually produced as unrounded $[\mathrm{u}] /[\mathrm{u}]$. Our claim is that these facts can be explained by assuming that the element $|U|$ has become weak in Japanese - and therefore, typically appears in its non-headed guise. This begs the question as to whether $|U|$ can ever be headed in this language. In the following section we show that it can. We discuss the contexts in which labial/rounded sounds are permitted, and describe the structural conditions that must be met in order for labiality/rounding (i.e. headed $|\underline{U}|)$ to be phonetically realised. 


\section{Dark versus light elements}

We propose that, for $|\mathrm{U}|$ to be headed and thus interpreted as labiality in Japanese, this element must co-occur with (i.e. be supported by) another element belonging to the same element group as $|\mathrm{U}|$. The group in question is the set of so-called 'dark' elements (Backley \& Nasukawa 2009).

In $\S 2$ we described how elements naturally divide into two groups, a resonance group $(|\mathrm{I}||\mathrm{U}||\mathrm{A}|)$ and a non-resonance group $(|\mathrm{P}||\mathrm{H}||\mathrm{L}|)$. However, there is also another way of dividing the element set, and this is based on the auditory/acoustic split between 'light' and 'dark'. The dark elements $|\mathrm{A}||\mathrm{U}||\mathrm{L}|$ all have acoustic energy concentrated at the lower end of the spectrum, whereas the light elements $|\mathrm{I}||\mathrm{H}||\mathrm{P}|$ display a more dispersed pattern in which energy is distributed more widely across the spectral range. Expressed in impressionistic terms, this produces a difference in timbre or sound quality: dark elements have a rich, warm, mellow character, while light elements sound bright, thin, and in some cases hissy or metallic.

$$
\begin{aligned}
& \text { dark elements: }|\mathrm{U}|,|\mathrm{A}|,|\mathrm{L}| \\
& \text { - } \quad \text { acoustic energy concentrated at the lower end of the } \\
& \text { - } \quad \text { rich, warm and mellow timbre } \\
& \text { light elements: }|\mathrm{I}|,|\mathrm{H}|,|\mathrm{P}| \\
& \text { - acoustic energy widely distributed across the spectrum } \\
& \text { - bright, thin (and hissy) timbre }
\end{aligned}
$$

To illustrate the point, consider the nature of so-called dark-l (cf. light- $l$ ) in English, also referred to as velarized-l. The dark quality of this sound comes from the presence of the element $|\mathrm{U}|$, which is non-headed and thus produces velar resonance (Backley 2011: 178). This compares with light-l, which contains the light element $|\mathrm{I}|$ in place of $|\mathrm{U}|$ and consequently has a quite different sound quality.

Dark and light are to be understood as informal labels rather than as formal linguistic categories. After all, they are defined in somewhat vague, impressionistic terms (e.g. 'rich', 'thin', 'widely dispersed energy'). Nevertheless, these informal labels do capture some useful generalisations about element behaviour. In particular, the relevance of the dark/light division becomes apparent in the context of the three aspects of spoken language given in (8): resonance, frequency, and colour. We argue that these are general properties of the speech signal that contribute to the overall identity of segments. 
(8)

\begin{tabular}{llll} 
& \multicolumn{2}{l}{ dark } & \multicolumn{2}{l}{ light } \\
RESONANCE & $|\mathrm{A}|$ resonance peak & $|\mathrm{P}|$ resonance drop \\
FREQUENCY & $|\mathrm{L}|$ low-freq. energy & $|\mathrm{H}|$ high-freq. energy \\
COLOUR & $|\mathrm{U}|$ dark, mellow & $|\mathrm{I}|$ bright, thin
\end{tabular}

Although resonance, frequency and colour are gradient properties, languages only refer to their extreme values in order to express contrasts. For example, high-frequency and low-frequency energy are both linguistically significant, whereas other values such as medium frequency and variable frequency are not. The grammar must therefore be able to refer to high frequency and low frequency as independent melodic properties - which is precisely the roles of the elements $|\mathrm{H}|$ and $|\mathrm{L}|$, respectively. Note that $|\mathrm{H}|$ and $|\mathrm{L}|$ create an opposing pair that is, they show polar values. And the same is also true of the remaining elements: $|\mathrm{A}|$ marks a peak of resonance while the opposing element |?| represents a sudden drop in (or absence of) resonance; meanwhile, $|\mathrm{I}|$ and $|\mathrm{U}|$ are opposites with respect to colour, where the term 'colour' refers to the timbre or sound quality mentioned above.

Motivation for the element pairings in (8) comes initially from the physical (acoustic) properties of each element. However, the pairings are also relevant to phonology, because they influence the way elements combine (Backley (in press)). And as we demonstrate below, this affects the kinds of melodic categories and segmental contrasts that we find in languages. In general, languages prefer to avoid segmental expressions that combine both the elements in one pair, one of them being dark and the other light. Thus, categories such as those in (9) are relatively marked cross-linguistically. For example, front rounded vowels such as $[\mathrm{y}]$ and [œ] combine the two colour elements: dark $|\mathrm{U}|$ (for round) and light $|\mathrm{I}|$ (for front). As polar values, $|\mathrm{U}|$ and $|\mathrm{I}|$ create a marked combination when compared with $|\mathrm{A}|+|\mathrm{I}|$ and $|\mathrm{A}|+|\mathrm{U}|$.

$\begin{array}{lll}\text { category } & \text { examples } & \text { dark + light } \\ \text { front rounded vowels } & {[\mathrm{y}],[œ]} & |\mathrm{U}|+|\mathrm{I}| \\ \text { voiced aspirated stops } & {\left[\mathrm{b}^{\mathrm{h}}\right],\left[\mathrm{g}^{\mathrm{h}}\right]} & |\mathrm{L}|+|\mathrm{H}| \\ \text { guttural consonants } & {[\mathrm{?}],[\mathrm{q}]} & |\mathrm{A}|+|\mathrm{P}|\end{array}$

Note that, although the combinations in (9) are marked, they cannot be ruled out completely. This is because each element exists as an independent phonological category, so in principle the grammar should be able to combine any element with any other element. In practice, however, some combinations of dark and light are disfavoured specifically, those that refer to the same speech signal property (i.e. frequency, resonance or colour). 
Given that some combinations of dark and light are disfavoured, especially from the same element pair, it is not surprising to find a general preference for expressions in which dark elements combine with other dark elements, and light with light. This tendency is highlighted by the behaviour of melodic enhancements. Enhancement is a way of increasing the acoustic prominence of a segment, and in turn, making it more distinct from other segments. And to enhance the salience of a light segment (i.e. a segment consisting predominantly of light elements), languages typically introduce another light property. An example comes from Navajo (Lavoie 2001), which has a contrast between the dark glide [u] and the light glide [j]. Arguably, the difference between [u] and [j] is difficult to perceive owing to the phonetic closeness of the two sounds. To increase the salience of this contrast, therefore, Navajo speakers have the option of reinterpreting the light glide [j] as a fricative [j]. Expressed in element terms, the palatal glide [j] consisting of just $|\mathrm{I}|$ is enhanced by the addition of another light element $|\mathrm{H}|$ to become a palatal fricative.

The division between dark and light elements is also relevant to the way segments are distributed within syllables: in general, the syllable onset favours light consonants whereas the syllable coda favours dark consonants. Light consonants include stops (with $\mid$ ?|) and fricatives $(|\mathrm{H}|)$, both of which naturally belong in syllable-initial position. This compares with dark consonants such as nasals (with $|\mathrm{L}|$ ) and liquids (with $|\mathrm{A}|^{4}$ ), which typically function as coda consonants. Velars and labials, both containing dark $|\mathrm{U}|$, show a preference for the syllable coda too. In English, for example, a pre-consonantal coda can contain a velar (e.g. doctor /dpk.tə/) or a labial (e.g. capture /kæp.tə/) as these sounds are represented by a dark element $|\mathrm{U}|$, but as a rule this position does not contain a coronal (e.g. */dpt.kə/) or palatal (e.g. *kæt).pə/) because coronals and palatals contain a light place element $|\mathrm{I}|$.

\section{The headedness of $|\mathbf{U}|$ in Japanese}

Returning to the issue of labials in Japanese, the question remains as to how we account for the limited distribution of labiality in the language. It will be recalled from section 3 that labiality (as lip rounding) is not realised in the back vowel $u$ (pronounced [u]) or the back glide $w$ (pronounced [u]). It was also mentioned that many of the labial stops which existed in earlier forms of Japanese have now disappeared. The

\footnotetext{
${ }^{4}$ For the analysis of liquids as $|\mathrm{A}|$-glides, see Backley (2011: 165ff).
} 
pertinent question should therefore focus on where labiality can be phonetically interpreted in the modern language.

The distribution of labial consonants is summarised in (10), where the underlined $|\underline{\underline{U}}|$ element is headed and realised as labial resonance.

\begin{tabular}{|c|c|c|c|}
\hline (10a) & $\begin{array}{l}m \\
b\end{array}$ & $\begin{array}{l}|\underline{\mathrm{U}} \mathrm{L}| \\
\mid \underline{\mathrm{U}} \mathrm{L} ? \mathrm{l}\end{array}$ & $\begin{array}{l}\text { me 'eye', ame 'rain', ammari 'not much' } \\
\text { basho 'place', nabe 'pan', zembu 'all' }\end{array}$ \\
\hline 10b) & $p$ & | & happa 'leaf', sampo 'stroll’ \\
\hline
\end{tabular}

The voiced consonants $m$ and $b$ in (10a) have an unrestricted distribution, occurring word-initially and word-medially; also, they can stand either as single consonants or as part of a geminate (e.g. ammari 'not much') or partial geminate (e.g. zembu 'all'). By contrast, the voiceless stop $p$ in (10b) is only found in geminates (e.g. happa 'leaf') and partial geminates (e.g. sampo 'stroll') - single $p$ does not appear in Japanese words except for some loanwords and mimetic words (see section 3.1 above). Here we show how this restriction on the occurrence of single $p$ reflects a characteristic of Japanese $|\mathrm{U}|$ which we have alluded to above, namely, that this element is inherently weak. Specifically, it is too weak to appear in its headed form |비 (and thus, too weak to be realised as labial resonance) unless it has additional structural support. We propose that this support comes from the presence of another dark element, either in the same expression or in another expression with which $p$ is prosodically linked.

Assuming that the set of dark elements comprises $\{|\mathrm{U}||\mathrm{L}||\mathrm{A}|\}$, as given in $\S 4$, it follows that a labial expression in Japanese not only contains $|\underline{\mathrm{U}}|$ but must also be associated with $|\mathrm{L}|$, or $|\mathrm{A}|$, or with another token of $|\underline{U}|$, in order for $|\underline{U}|$ to retain its head status and be phonetically interpreted as labial resonance. The structures in (11a) meet this condition whereas the structure for $p$ in (11b) does not.

\begin{tabular}{|c|c|}
\hline labic & expression \\
\hline$m$ & $|\underline{\mathrm{U}} \mathrm{L}|$ \\
\hline$b$ & $|\underline{U} \underline{L} ?|$ \\
\hline$p-p$ & 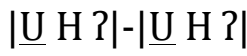 \\
\hline$m-p$ & $\mid \underline{U}$ L $?|-| \underline{U}$ H $? \mid$ \\
\hline$p$ & |므 H ?| \\
\hline
\end{tabular}

supporting dark element
nasal $|\mathrm{L}|$
voicing $|\underline{\mathrm{L}}|$
prosodically linked $|\underline{\mathrm{U}}|$
prosodically linked $|\underline{\mathrm{U}}|$
none

First, let us consider the well-formed structures in (11a). In $m,|\underline{\mathbf{U}}|$ is supported by the nasal element $|\mathrm{L}|$ so the expression $|\underline{\mathrm{U}} \mathrm{L}|$ can be phonetically interpreted as a labial. The same is true of $b$, in which $|\underline{U}|$ is again supported by $|\mathrm{L}|$ (this time in its headed form $|\underline{\mathrm{L}}|$, representing

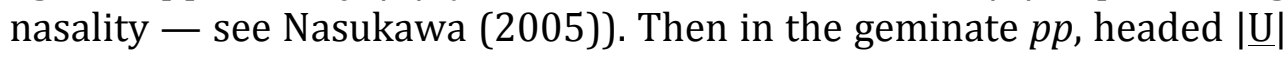


in the head (i.e. 'licensing') position of the geminate structure is supported by the presence of an identical headed $|\underline{U}|$ in the dependent position, thus allowing labial resonance to be realised in the double consonant. For the same reason the partial geminate $m p$ is also a wellformed labial expression.

The only structure which cannot support labiality is the single (i.e. non-geminate) stop $p$ in (11b), since its structure contains a headed |ㅁ| element which is not supported by another dark element. And significantly, single $p$ is the only labial consonant which has not survived into the modern language. Although single $p$ was present in older forms of Japanese, it has since become an ill-formed structure. Its ungrammatical status in modern Japanese may be seen as resulting from a weakening of the $|U|$ element which took place at a relatively early stage in the history of the language. Moreover, this weakening appears to have led to the introduction of a concomitant structural condition on the realisation of headed $|\underline{U}|$ as labiality. This condition requires $|\underline{U}|$ to be supported by another dark element - a condition which historical (single) $p$ fails to satisfy because no supporting (dark) element is present in its structure.

Given that the inherent nature of $|\mathrm{U}|$ in Japanese has changed over time by becoming weaker, we propose the novel idea that diachronic change may take the form of a change in the strength of an element. As a result of this diachronic weakening effect, Japanese $|U|$ can no longer exist in its 'strong' headed form $|\underline{U}|$ unless a particular structural condition is met: it must be supported by another element from the same group of dark elements. We have shown how this can help account for the distribution of labial consonants and rounded vowels in the present-day language. The situation in modern Japanese is summarised in (12) and (13).

$$
\begin{aligned}
& \text { labiality/rounding absent } \\
& u \quad[\mathrm{u}]\left({ }^{*}[\mathrm{u}]\right) \quad|\mathrm{U}| \\
& w \quad[u](*[\mathrm{w}]) \quad|\mathrm{U}| \\
& k \quad[\mathrm{k}] \quad \mid \mathrm{UH} \text { ? }
\end{aligned}
$$

(13) labiality/rounding interpreted

$\begin{array}{lll}o & {[\mathrm{o}](*[\gamma])} & |\underline{\mathrm{U}} \mathrm{A}| \\ m & {[\mathrm{~m}]} & |\underline{\mathrm{U}} \mathrm{L}| \\ b & {[\mathrm{~b}]} & \mid \underline{\mathrm{U}} \mathrm{L} \text { ? } \\ p & {[\mathrm{pp}]} & \mid \underline{\mathrm{U}} \text { H } ~-\underline{\mathrm{U}} \text { H } ~\end{array}$

Referring to the expressions in (13), $|\mathrm{U}|$ may appear in its headed form $|\underline{\mathrm{U}}|$ if it is associated with $|\mathrm{A}|$ (in $o$ ), or $|\mathrm{L}|$ (in $m, b$ ), or another $|\underline{\mathrm{U}}|$ 
(in $p p$ ). This headed $|\underline{\mathrm{U}}|$ is phonetically interpreted as labiality or lip rounding. But in the absence of a co-occurring dark element, strong $|\underline{\mathrm{U}}|$ cannot be interpreted and a non-headed $|U|$ stands in its place. Nonheaded $|\mathrm{U}|$ is a property of the velar consonants and back unrounded vowels/glides in (12).

Finally, we note that the same structural requirement also applies in the vowel system of modern Japanese: for $|\underline{\mathrm{U}}|$ to be interpreted as labiality (i.e. lip rounding), another dark element must be present locally. It was pointed out above that the high back vowel $u$ is typically realised as an unrounded [u] in modern Japanese, whereas the mid back vowel $o$ is always produced as a rounded [o]. Again, the distribution of labiality/rounding can be explained by referring to the element structure of the segments involved. The high vowel $u$ is represented by a sole $|\mathrm{U}|$ element, but because of the labiality requirement just described - and crucially, because no dark element is available to support this $|\mathrm{U}|$ - it cannot be headed, and as a result, cannot be realised as a rounded vowel. As a non-headed expression it has the interpretation [u], i.e. back and high, but unrounded. By contrast, the mid vowel $o$ has the structure $|\underline{U} A|$, in which the dark element $|\mathrm{A}|$ provides the necessary support to allow $|\underline{\mathrm{U}}|$ to be headed, and hence, to be phonetically interpreted with lip rounding.

\section{Conclusion}

In segmental phonology there is an underlying assumption that the units of melodic structure (i.e. features, elements) display characteristics that are cross-linguistically consistent. For example, we expect [+continuant] to have the same value in all languages; similarly, we expect $|\mathrm{H}|$ to be associated with the same basic properties, no matter which language we are describing. In this paper, however, we have challenged this assumption of cross-linguistic uniformity by claiming that in Japanese the $|U|$ element shows a clear languagespecific trait - it appears to be naturally weak.

In the preceding discussion it was noted that the generalisations we have described - in particular, the restricted appearance of nongeminate $p-$ apply primarily to the native vocabulary of Japanese. They do not necessarily apply to loanwords (e.g. peepaa [pe:pa:] 'paper') or to mimetic words (e.g. pera-pera [perapera] 'fluent'), in which single $p$ appears to have a free distribution. As noted in footnote 4, on this point we follow Itô \& Mester (1999) and Vance (1987), who recognise the advantages of dividing the Japanese lexicon into distinct strata (i.e. native Yamato words, Sino-Japanese words, Western loanwords, mimetic/expressive words) where each stratum may 
display different phonological patterns because it is subject to different rules or conditions. At the same time, we acknowledge that this view is not universally accepted, and that further investigation is needed into the question of whether native Japanese speakers do indeed make formal divisions within the lexicon based on etymology, or whether such classifications are merely the result of linguists' observations and users' experience of the native language.

On the assumption that Japanese phonology is indeed sensitive to the difference between native and borrowed vocabulary, we maintain that the patterns of distribution described above can be explained only by assuming a natural division between dark and light elements. On further investigation it may emerge that the dark/light division has a wider, more general role to play in the description of phonological patterning cross-linguistically.

\section{Comments invited}

PiHPh relies on post-publication review of the papers that it publishes. If you have any comments on this piece, please add them to its comments site. You are encouraged to consult this site after reading the paper, as there may be comments from other readers there, and replies from the author. This paper's site is here:

http://dx.doi.org/10.2218/pihph.1.2016.1703

\section{Acknowledgements}

This research was first presented at the Second Edinburgh Symposium on Historical Phonology, hosted by the University of Edinburgh on 3-4 December 2015. We thank the conference participants for their constructive comments. This work was partially funded by grants (26284067 and 15K02611) from the Japanese government (Grant-inAid for Scientific Research (B) and (C), Ministry of Education, Culture, Sports, Science and Technology (MEXT)).

\section{Author contact details}

\section{Phillip Backley \& Kuniya Nasukawa}

Tohoku Gakuin University

1-3-1 Tsuchitoi

Aoba-ku

Sendai, Japan, 980-8511

backley@mail.tohoku-gakuin.ac.jp, nasukawa@mail.tohoku-gakuin.ac.jp 


\section{References}

Backley, Phillip. 2011. An introduction to Element Theory. Edinburgh: Edinburgh University Press.

Backley, Phillip. 2012. Variation in Element Theory. Language Variation 12(1). 57-102.

Backley, Phillip. In press. Head-dependent relations in Element Theory: binarity and multiple heads. To appear in Glossa.

Backley, Phillip \& Kuniya Nasukawa. 2009. Representing labials and velars: a single 'dark' element. Phonological Studies 12. 3-10.

Backley, Phillip \& Kuniya Nasukawa. 2010. Consonant-vowel unity in Element Theory. Phonological Studies 13. 21-28.

Cyran, Eugeniusz. 2010. Complexity scales and licensing in phonology. Berlin and New York: Mouton de Gruyter.

Harris, John \& Geoff Lindsey. 1995. The elements of phonological representation. In Jacques Durand \& Francis Katamba (eds.), Frontiers of phonology: Atoms, structures, derivations, 34-79. Harlow, Essex: Longman.

Itô, Junko \& Armin Mester. 1999. The phonological lexicon. In Natsuki Tsujimura (ed.), The handbook of Japanese linguistics, 62-100. Malden, Massachusetts and Oxford: Blackwell.

Komatsu, Hideo. 1981. Nihongo no On'in (Nihongo no Sekai 7) [The Phonology of Japanese (The World of Japanese 7)]. Tokyo: Chûô Kôronsha.

Lavoie, Lisa. 2001. Consonant strength: Phonological patterns and phonetic manifestations. New York and London: Garland.

Martin, Samuel E. 1987. The Japanese language through time. New Haven and London: Yale University Press.

Nasukawa, Kuniya. 2005. A unified approach to nasality and voicing. Berlin and New York: Mouton de Gruyter.

Nasukawa, Kuniya \& Phillip Backley. 2008. Affrication as a performance device. Phonological Studies 11. 35-46.

Nasukawa, Kuniya \& Phillip Backley. 2011. The internal structure of ' $r$ ' in Japanese. Phonological Studies 14. 27-34.

Okumura, Mitsuo. 1972. Kodai no On'in. In Norio Nakata (ed.), Koza Nihongoshi 2: On'inshi, Mojishi, 63-171. Tokyo: Taishukan.

Shibatani, Masayoshi. 1990. The languages of Japan. Cambridge: Cambridge University Press.

Tsukishima, Hiroshi. 1964. Kokugogaku. Tokyo: Tokyo Daigaku.

Vance, Timothy. 1987. An introduction to Japanese phonology. New York: State University of New York Press.

Ueda, Kazutoshi. 1898. P-Onkoo [On the Sound P]. Teikoku Bungaku 4-1. 